\title{
Is birth weight associated with pregestational maternal BMI? BRISA Cohort, Ribeirão Preto, Brazil
}

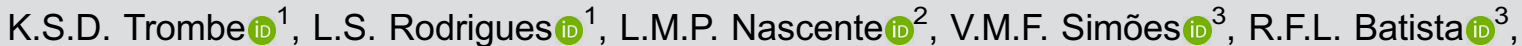 \\ R.C. Cavalli $\mathbb{1}^{4}$, C. Grandi $\left(^{5}{ }^{5}\right.$, and V.C. Cardoso ${ }^{2}{ }^{2}$ \\ ${ }^{1}$ Programa de Pós-Graduação em Saúde da Criança e do Adolescente, Faculdade de Medicina de Ribeirão Preto, \\ Universidade de São Paulo, Ribeirão Preto, SP, Brasil \\ ${ }^{2}$ Departamento de Puericultura e Pediatria, Faculdade de Medicina de Ribeirão Preto, \\ Universidade de São Paulo, Ribeirão Preto, SP, Brasil \\ ${ }^{3}$ Departamento de Saúde Pública, Universidade Federal do Maranhão, São Luís, MA, Brasil \\ ${ }^{4}$ Departamento de Ginecologia e Obstetrícia, Faculdade de Medicina de Ribeirão Preto, \\ Universidade de São Paulo, Ribeirão Preto, SP, Brasil \\ ${ }^{5}$ Research Committee, Argentine Society of Pediatrics, Buenos Aires, Argentina
}

\begin{abstract}
Given the increase of women with excess weight or obesity and its possible effects on birth weight, the present study aimed to investigate the association between pregestational maternal body mass index (BMI) and birth weight in a birth cohort from Ribeirão Preto, SP, Brazil. This was a prospective study conducted on 1362 mother-child pairs involving singleton births. The women were evaluated using standardized questionnaires during the second trimester of pregnancy and at the time of childbirth. Information about the newborns was obtained from their medical records. The dependent variable was birth weight, categorized as low, adequate, or high. The independent variable was pregestational maternal BMI, categorized as malnutrition, adequate weight, overweight, and obesity. A multinomial regression model was used to estimate the crude and adjusted relative risk (RR) of low and high birth weight. A high frequency of pregestational excess weight $(39.6 \%)$ was detected and found to be independently associated with high birth weight $(\mathrm{RR}=2.13,95 \% \mathrm{Cl}: 1.19-3.80$ for overweight and $\mathrm{RR}=3.34,95 \% \mathrm{Cl}$ : $1.80-6.19$ for obese pregnant women). There was no association between pregestational malnutrition and low birth weight (RR=1.70; $95 \%$ $\mathrm{Cl}$ : 0.81-3.55). The present data showed a high rate of women with excess pregestational weight, supporting the hypothesis that pregestational BMI may contribute to high birth weight babies and indicating the need for actions aiming to prevent excessive weight in women at reproductive age.
\end{abstract}

Key words: Birth weight; Body mass index; Cohort study; Overweight; Obesity

\section{Introduction}

Birth weight is considered the main indicator of newborn health in both epidemiological studies and clinical practice given its strong association with morbidity-mortality at the beginning of life (1). Low- and high-birth weight newborns (NB) have a higher risk of perinatal death and other negative outcomes during childhood, adolescence, and adulthood (1-3).

Birth weight is the result of the interaction of biological, socioeconomic, and psychological factors. Among the biological factors, particularly important are the genetic background of mother and fetus, the maternal nutritional and metabolic status, the exposure of the binomial to diseases and toxins, the functioning of the placenta, and finally, the obstetric characteristics (4). Several authors have also considered factors such as pregestational maternal weight and height and maternal weight gain during pregnancy to be strongly associated with birth weight (5-7).

Studies have shown that pregestational maternal malnutrition may increase the risk of preterm birth, low birth weight, and small for gestational age (SGA) NB (810). Conversely, excess pregestational weight increases the risk of high birth weight and large for gestational age (LGA) NB $(9,11,12)$, which in turn is related to overweight and/or obesity during the life cycle $(9,11)$. Also, research on the association between an adverse environment from the beginning of life and the subsequent development of non-communicable diseases has allowed an understanding of the origin of some metabolic diseases, such as diabetes and obesity, certain types of cancer, and some 
disorders in neurodevelopment, educational development, reproductive health, and mental health (13).

Population studies conducted in Brazil estimated a $25.2 \%$ rate of obesity $(14,15)$ and a $34.6 \%$ rate of overweight among women in 2013 (15). Among pregnant women, birth cohort studies conducted in Pelotas, RS, detected a mean increase of $11.5 \mathrm{~kg}$ in pregestational weight between 1982 and 2015 and an increase in the rate of overweight and obesity among women from 22.1 to $47 \%$ during the same period (16).

Thus, because of the increase of women with excess weight or obesity and its possible effects on birth weight, the objective of the present study was to assess the association between pregestational maternal body mass index (BMI) and birth weight in a prenatal cohort from Ribeirão Preto, SP, Brazil.

\section{Material and Methods}

This was a prospective study using data from the prenatal cohort of the study "Etiological factors of preterm birth and consequences of perinatal factors for children's health: a birth cohort from two Brazilian cities - BRISA", conducted in Ribeirão Preto and São Luís (17) in 2010. However, only the Ribeirão Preto data were included and a cross-sectional analysis was performed.

The cohort sample size was calculated according to the reported prevalence of the explanatory variables of the project, which ranged from 10 to $50 \%$ and considering a predicted rate of prematurity of $12 \%$. Consequently, 1500 pregnant women were recruited in Ribeirão Preto.

Pregnant women were invited to participate in the study during the first trimester; prenatal visits were held in hospitals and health clinics of the city. Obstetrical ultrasound was performed up to week 20 of gestation to estimate gestational age (GA). During the second trimester, between weeks 20 and 25 GA, they were evaluated using a standardized questionnaire regarding sociodemographic, general health, and reproductive characteristics. On that occasion, a total of 1400 pregnant women reported their pregestational weight, whereas their height was measured.

The participants were reevaluated at childbirth using a second standardized questionnaire when NB anthropometric data were also collected from their medical records. Data were collected from January 2010 to July 2011 for a total of 1370 mother-child pairs. Women whose weight and/or height measurements were not available were excluded from the study, resulting in a sample of 1362 women.

The dependent variable (birth weight) was classified as low when less than $2500 \mathrm{~g}$, adequate when $2500 \mathrm{~g}$ and less than $4000 \mathrm{~g}$, and high when $4000 \mathrm{~g}$ or more, according to $\mathrm{WHO}(18)$.

Pregestational BMI (weight/height ${ }^{2}$ ), the independent variable, was categorized as malnutrition when below

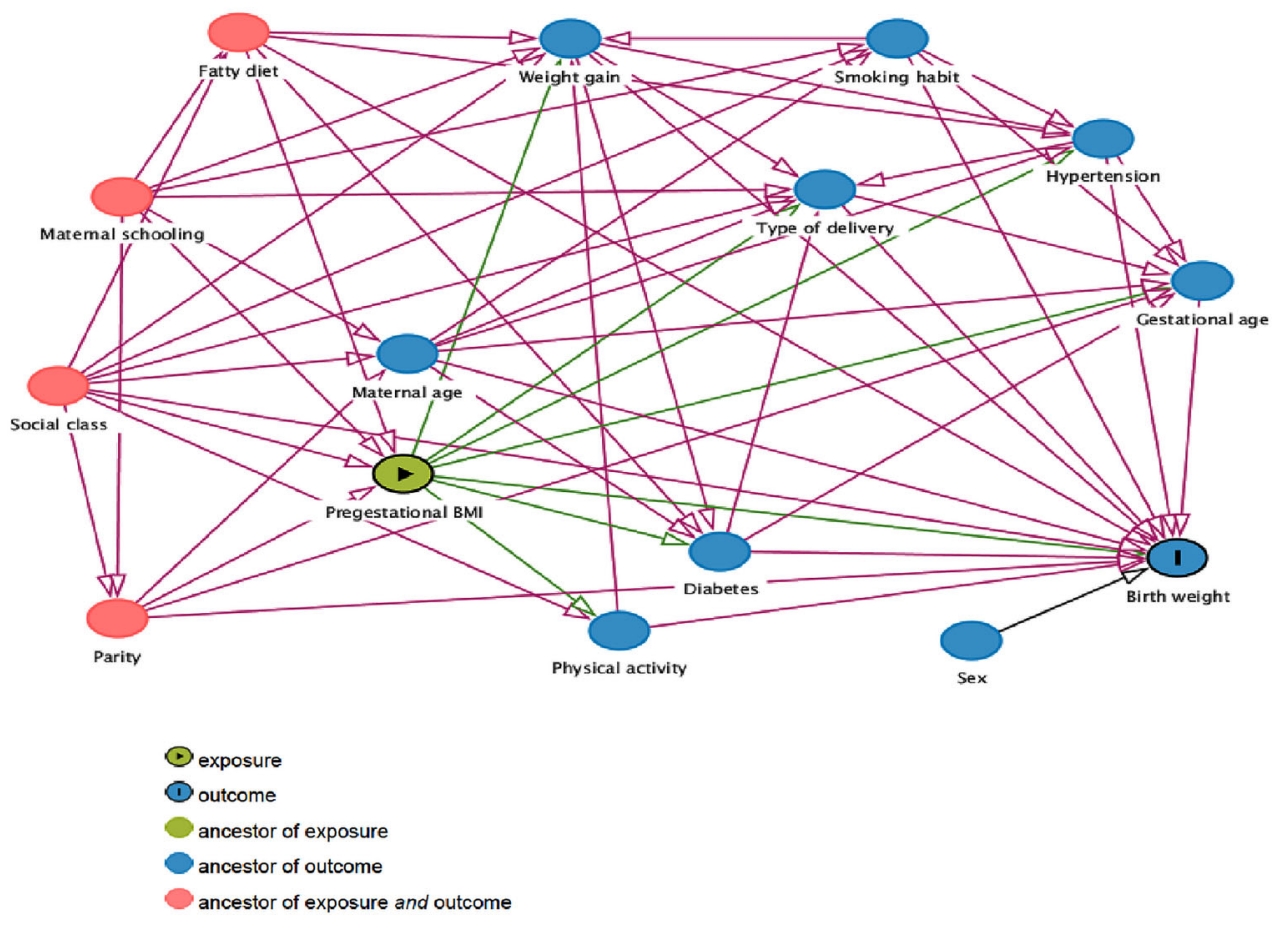

Figure 1. Theoretical model of the association between pre-gestational body mass index (BMI) and birth weight. 
$18.5 \mathrm{~kg} / \mathrm{m}^{2}$, adequate if $18.5 \mathrm{~kg} / \mathrm{m}^{2}$ or higher and less than $25 \mathrm{~kg} / \mathrm{m}^{2}$, overweight if $25 \mathrm{~kg} / \mathrm{m}^{2}$ or higher and less than $30 \mathrm{~kg} / \mathrm{m}^{2}$, and obesity if $30 \mathrm{~kg} / \mathrm{m}^{2}$ or more (19).

To determine the association of pregestational BMI with birth weight, a theoretical model was designed (Figure 1) using Directed Acyclic Graphs (DAG), generated by DAGitty software, version $2.3(20)$, which allowed to identify confounding variables to be controlled for.

Maternal variables used in DAG were: schooling $(8,9$ 11 , or $\geqslant 12$ years of study), age (up to 19 years, 2034 years, or $\geqslant 35$ years), economic class based on the instrument elaborated by the Brazilian Association of Research Enterprises (ABEP) (A/B, C, and D/E, A1/A2 being the highest), parity $(1,2-3$, and 4 or more children), smoking during pregnancy (at least one cigarette at any point in the pregnancy, yes or no), diet (high or low in fat), level of physical activity during pregnancy (no activity, mild, moderate, or high activity), gestational diabetes (yes or no), gestational hypertension (yes or no), type of delivery (cesarean or vaginal), gestational weight gain (calculated as the difference between weight at the end of pregnancy and weight before pregnancy), gestational age (weeks), and NB sex. The fat content of the diet was assessed using the Block Score (21) and the level of physical activity was assessed using the Short form of the International Physical Activity Questionnaire (IPAQc) (22).

Data are reported as means $\pm S D$ or proportions, whichever is appropriate. Statistical tests included ANOVA or chi-squared tests. The DAGitty software provided a

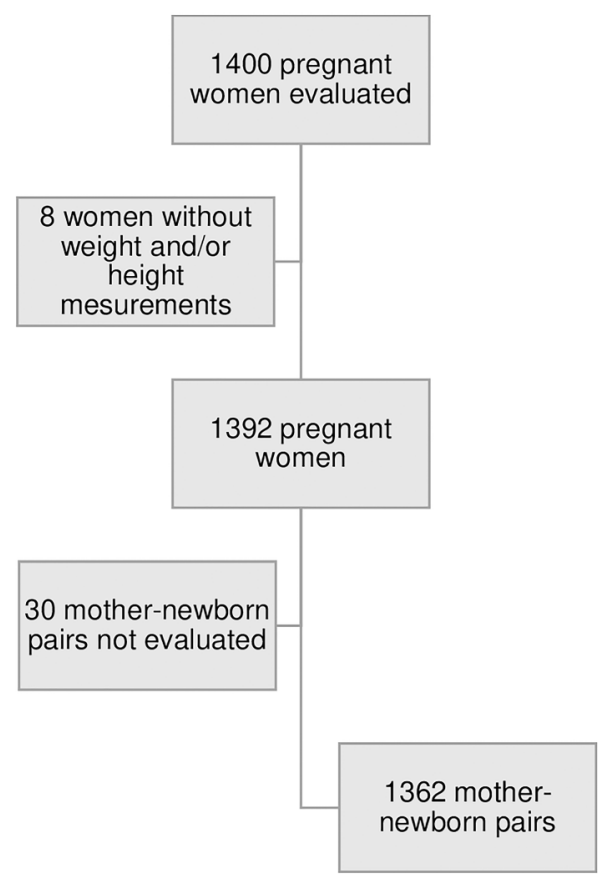

Figure 2. Flowchart of the study population.
Table 1. Maternal and newborn characteristics. BRISA Cohort, Ribeirão Preto, 2010.

\begin{tabular}{|c|c|c|}
\hline Characteristics & $\mathrm{n}$ & $\%$ \\
\hline \multicolumn{3}{|l|}{ Maternal } \\
\hline \multicolumn{3}{|l|}{ Maternal pregestational BMI* } \\
\hline Malnutrition & 101 & 7.4 \\
\hline Adequate & 722 & 53.0 \\
\hline Overweight & 346 & 25.4 \\
\hline Obesity & 193 & 14.2 \\
\hline \multicolumn{3}{|l|}{ Maternal age } \\
\hline Up to 19 years & 192 & 14.0 \\
\hline 20-34 years & 1040 & 75.9 \\
\hline$\geqslant 35$ years & 138 & 10.1 \\
\hline \multicolumn{3}{|l|}{ Parity } \\
\hline 1 child & 676 & 49.3 \\
\hline $2-3$ children & 593 & 43.3 \\
\hline 4 or more children & 101 & 7.4 \\
\hline \multicolumn{3}{|l|}{ Maternal schooling ${ }^{*}$} \\
\hline Up to 8 years & 114 & 8.4 \\
\hline $9-11$ years & 856 & 63.0 \\
\hline$\geqslant 12$ years & 388 & 28.6 \\
\hline \multicolumn{3}{|l|}{ Social class (ABEP) } \\
\hline $\mathrm{A} / \mathrm{B}$ & 365 & 28.3 \\
\hline C & 778 & 60.2 \\
\hline $\mathrm{D} / \mathrm{E}$ & 149 & 11.5 \\
\hline \multicolumn{3}{|l|}{ Diet (Block score) ${ }^{*}$} \\
\hline Low in fat & 979 & 71.6 \\
\hline High in fat & 389 & 28.4 \\
\hline \multicolumn{3}{|l|}{ Smoking during pregnancy } \\
\hline Yes & 174 & 12.7 \\
\hline No & 1196 & 87.3 \\
\hline \multicolumn{3}{|l|}{ Gestational hypertension } \\
\hline Yes & 192 & 14.0 \\
\hline No & 1178 & 86.0 \\
\hline \multicolumn{3}{|l|}{ Gestational diabetes } \\
\hline Yes & 73 & 5.3 \\
\hline No & 1297 & 94.7 \\
\hline \multicolumn{3}{|l|}{ Level of physical activity* } \\
\hline No activity & 217 & 16.1 \\
\hline Light & 426 & 31.5 \\
\hline Moderate & 417 & 30.8 \\
\hline High & 292 & 21.6 \\
\hline \multicolumn{3}{|l|}{ Type of delivery } \\
\hline Cesarean & 817 & 59.6 \\
\hline Vaginal & 553 & 40.4 \\
\hline \multicolumn{3}{|l|}{ Newborns } \\
\hline \multicolumn{3}{|l|}{ Gender } \\
\hline Female & 673 & 49.1 \\
\hline Male & 697 & 50.9 \\
\hline \multicolumn{3}{|l|}{ Weight ${ }^{*}$} \\
\hline Low & 105 & 7.7 \\
\hline Adequate & 1187 & 86.8 \\
\hline High & 75 & 5.5 \\
\hline Gestational age (weeks, mean \pm SD) & $39 \pm 2.1$ & \\
\hline
\end{tabular}

BMI: body mass index; ABEP: Brazilian Association of Research Companies. *Unknown values were excluded. 
minimum adjustment model for the estimate of the total effect of the explanatory variable on the outcome, including the following variables: social class, diet, maternal schooling, and parity (Figure 1). Subsequently, a multinomial regression model was used to estimate the crude and adjusted relative risk (RR) of low and high birth weight. All statistical analyses were performed using the statistical package Stata, version 13.0 (StataCorp LP; USA). A P-value $<0.05$ was considered significant.

The project was approved by the Research Ethics Committee of the University Hospital, Ribeirão Preto Medical School, University of São Paulo (protocol No. $8776 / 2012$ ), and all subjects gave written informed consent to participate in the study.

\section{Results}

Figure 2 presents the flowchart of the study population. Overweight was observed in $25.4 \%$ and obesity in $14.2 \%$ of pregnant women; $14 \%$ were adolescents, $49.3 \%$ were primiparous, $8.4 \%$ had a lower level of schooling, $28.4 \%$ had a diet rich in fat, $12.7 \%$ were smokers, $14 \%$ had gestational hypertension, $5.3 \%$ had gestational diabetes, $16.1 \%$ were sedentary, and $59.6 \%$ had a cesarean section (Table 1). Mean gestational age at birth was 39 weeks (SD 2.1), the rate of preterm births was $9.7 \%$, and the rate of low birth weight and high birth weight was 7.7 and $5.5 \%$, respectively.

Mean maternal BMl and pregestational weight was $24.6 \mathrm{~kg} / \mathrm{m}^{2}$ (SD 5.3) and $63.7 \mathrm{~kg}$ (SD 14.6), respectively, whereas mean weight gain during pregnancy was $14.6 \mathrm{~kg}$ (SD 6.1). Mean maternal weight gain during pregnancy decreased with increasing pregestational BMI, being higher than the Institute of Medicine's (IOM) recommendations (23) (Table 2).

Mean birth weight increased significantly with increasing maternal pregestational BMI (Table 3).

Maternal pregestational malnutrition was not associated with low birth weight risk, whereas in adjusted models, maternal overweight and obesity were significantly associated with a two-fold increase and a three-fold increase of high weight risks, respectively (Table 4).

\section{Discussion}

The present findings showed that maternal pregestational overweight and obesity were associated with high birth weight, whereas maternal pregestational malnutrition was not associated with low or high birth weight.

The nutritional transition was responsible for an alarming worldwide increase in overweight and obesity among women of reproductive age $(24,25)$. In the present study, mean pregestational BMI was within the upper limits of normality and almost $40 \%$ of the women studied were overweight or obese, in agreement with data reported for other Brazilian cities (16,26-28). These studies show a greater proportion of excess weight than detected in other populations like Peru (29), Holland (11), Lebanon (10), and Indonesia (30), but lower than that detected in the USA (31).

Previous studies have shown an association of increased pregestational BMI with high birth weight $(9,11,12,32)$. In addition, obese women with higher gestational weight gain show increased risks of cesarean delivery, labor induction, and postpartum hemorrhage. On the other hand, macrosomia was associated with a higher rate of admission of newborns to the neonatal intensive care unit and higher perinatal mortality (33).

However, some studies have observed that overweight/obese women also had an increased risk of SGA

Table 3. Birth weight according to maternal pregestational BMI. BRISA Cohort, Ribeirão Preto, 2010.

\begin{tabular}{lcc}
\hline Pregestational maternal BMI $\left(\mathrm{kg} / \mathrm{m}^{2}\right)$ & $\mathrm{n}$ & $\frac{\text { Birth weight }(\mathrm{g})}{$\cline { 3 - 3 }} \\
& & Mean $\pm \mathrm{SD}^{*}$ \\
\hline 18.5 & 101 & $3066 \pm 458^{*}$ \\
$18.5-24.9$ & 722 & $3158 \pm 524$ \\
$25-29.9$ & 346 & $3239 \pm 567$ \\
$\geqslant 30$ & 193 & $3299 \pm 636$ \\
\hline
\end{tabular}

BMI: body mass index; SD: standard deviation. * $P<0.001$, oneway analysis of variance.

Table 2. Maternal weight gain during pregnancy according to pregestational maternal BMI. BRISA Cohort, Ribeirão Preto, 2010

\begin{tabular}{lccc}
\hline Pregestational maternal BMI $\left(\mathrm{kg} / \mathrm{m}^{2}\right)$ & $\mathrm{n}$ & Weight gain during pregnancy $(\mathrm{kg})$ & IOM recommendation $(\mathrm{kg})$ \\
\cline { 2 - 3 } & & Mean $\pm \mathrm{SD}^{*}$ & \\
\hline$<18.5$ & 95 & $16.06 \pm 6.10$ & $12.5-18$ \\
$18.5-24.9$ & 667 & $15.06 \pm 5.77$ & $11.5-16$ \\
$25-29.9$ & 310 & $14.19 \pm 6.17$ & $7-11$ \\
$\geqslant 30$ & 149 & $12.29 \pm 6.40$ & $5-9.1$ \\
\hline
\end{tabular}

BMI: body mass index; SD: standard deviation; IOM: Institute of Medicine. ${ }^{*} \mathrm{P}<0.001$, one-way analysis of variance. 
Table 4. Crude and adjusted relative risks of low weight and high birth weight according to maternal pregestational BMI. Ribeirão Preto, 2010.

\begin{tabular}{|c|c|c|c|c|}
\hline \multirow[t]{2}{*}{ Pregestational maternal BMI } & \multicolumn{2}{|c|}{ Crude Relative Risk } & \multicolumn{2}{|c|}{ Adjusted Relative Risk* } \\
\hline & $\begin{array}{r}\text { Risk for LBW } \\
\text { RR }(95 \% \mathrm{Cl})\end{array}$ & $\begin{array}{r}\text { Risk for HBW } \\
\text { RR }(95 \% \mathrm{Cl})\end{array}$ & $\begin{array}{r}\text { Risk for LBW } \\
\text { RR }(95 \% \mathrm{Cl})\end{array}$ & $\begin{array}{r}\text { Risk for HBW } \\
\text { RR }(95 \% \mathrm{Cl})\end{array}$ \\
\hline Adequate & 1 & 1 & 1 & 1 \\
\hline Malnutrition & $1.32(0.65-2.69)$ & $0.28(0.04-2.13)$ & $1.70(0.81-3.55)$ & $0.31(0.04-2.33)$ \\
\hline Overweight & $1.14(0.71-1.83)$ & $2.29(1.30-4.03)$ & $1.05(0.63-1.76)$ & $2.13(1.19-3.80)$ \\
\hline Obesity & $0.98(0.52-1.85)$ & $3.43(1.87-6.29)$ & $1.01(0.52-1.96)$ & $3.34(1.80-6.19)$ \\
\hline
\end{tabular}

*Adjusted for economic class, maternal schooling, diet, and parity. BMI: body mass index; LBW: low birth weight; HBW: high birth weight; RR: relative risk; Cl: confidence interval.

babies (34), while others showed neither association with low birth weight nor macrosomic babies (35).

The BRISA Cohort study from São Luís-MA (28) estimated that $4 \mathrm{~kg} / \mathrm{m}^{2}$ gain in pregestational BMI was correlated with a $68 \mathrm{~g}$ increase in birth weight. The North American Healthy Start study concluded that for each $1 \mathrm{~kg} / \mathrm{m}^{2}$ increase in pregestational BMl there was a $5.2 \mathrm{~g}$ increase in fat mass, $7.7 \mathrm{~g}$ in lean mass, and $0.12 \%$ in percent body fat in newborns (31). Soltani et al. (30) detected an adjusted odds ratio of 13.4 for macrosomia in obese Indonesian pregnant women.

In contrast to previous reports $(8,9)$, in the present study, maternal malnutrition was not associated with low or high birth weight. A study of 24,241 pregnancies conducted in Aberdeen, Scotland, reported an adjusted odds ratio of $1.7(95 \% \mathrm{Cl}$ : $1.2-2.0)$ for malnourished pregnant women associated with low birth weight (32). Another study of 9,613 births conducted in Argentina detected a weak association between low pregestational $\mathrm{BMI}$ and low birth weight by multiple regression models $\left(R^{2} 0.37\right)(6)$.

The distribution of birth weight in low, adequate, and high categories was similar to that observed in the São Luis-MA birth cohort in 2010 and in the Pelotas-RS birth cohort in 2015, which strengthens the representativeness of the study $(36,37)$.

Theoretically, since Ribeirão Preto has a high human development index compared with other Brazilian cities (38), the malnourished group is due more to biotype than to calorie deprivation, explaining the lower impact of maternal malnutrition on birth size.

Several strategies have been proposed for the analysis of pregestational maternal weight as an exposure variable to reduce bias, minimize confounding, and quantify the contribution of measurement error. Among these strategies are DAG for selection of variables in multivariable models, the use of a flexible approach for the modeling of pregestational BMI (such as fractional polynomials or restricted cubic splines) to examine $U$ - or
J-shaped associations with adverse health outcomes, and the use of quantitative bias analysis to evaluate the potential bias due to measurement error in the selfreported weight. The inclusion of these methods is important because pregestational BMI often has a nonlinear relationship with the outcomes of interest (39).

The main strengths of the present study are its methodology, the use of DAG, and the possibility of comparing its findings with those from other Brazilian cities' cohorts. A limitation was a potential information bias since pregestational weight was self-reported by the participants. However, a systematic review demonstrated that, even if this type of error occurs, it does not interfere significantly with the results of epidemiological perinatal studies (40). Furthermore, it should be pointed out that the sample size was not originally calculated for $\mathrm{BMI}$ assessment and therefore type I error cannot be ruled out.

We conclude that maternal pregestational overweight and obesity were associated with high birth weight in this birth cohort, whereas there was no association between maternal malnutrition and low birth weight. Considering the impact of high birth weight on negative mother-child health outcomes, it is important to reinforce public health policies in order to reduce excess weight among women of reproductive age.

\section{Acknowledgments}

We acknowledge the women who generously contributed with information to the research. This study was supported by Fundação de Amparo à Pesquisa do Estado de São Paulo (FAPESP; Process No. 08/53593-0), Fundação de Apoio ao Ensino, Pesquisa e Assistência do Hospital das Clínicas, Faculdade de Medicina de Ribeirão Preto, Universidade de São Paulo (FAEPA), and Bolsa de Pós-Graduação da Coordenação de Aperfeiçoamento de Pessoal de Nível Superior (CAPES/ PROAP). 


\section{References}

1. World Health Organization. UNICEF-WHO low birthweight estimates: levels and trends 2000-2015. United Nations Children's Fund (UNICEF); 2019.

2. Knop MR, Geng T, Gorny AW, Ding R, Li C, Ley SH, et al. Birth weight and risk of type 2 diabetes mellitus, cardiovascular disease, and hypertension in adults: a meta-analysis of 7646267 participants from 135 studies. J Am Heart Assoc 2018; 7: e008870, doi: 10.1161/JAHA.118.008870.

3. Victora CG, Adair L, Fall C, Hallal PC, Martorell R, Richter L, et al. Maternal and child undernutrition: consequences for adult health and human capital. Lancet 2008; 371: 340-357, doi: 10.1016/S0140-6736(07)61692-4.

4. Kramer MS. Determinants of low birth weight: methodological assessment and meta-analysis. Bull World Health Organ 1987; 65: 663-737.

5. Council NR. Influence of pregnancy weight on maternal and child health: workshop report. National Academies Press; 2007. p 116.

6. Grandi CA. Relationship between maternal anthropometry and weight gain with birth weight, low birth weight, small for date and prematurity at an urban population of Argentina [in Spanish]. Arch Latinoam Nutr 2003; 53: 369-375.

7. Estrada-Restrepo A, Restrepo-Mesa SL, Feria NDCC, Santander FM. Factores maternos relacionados con el peso al nacer de recién nacidos a término, Colombia, 2002-2011 [in Spanish]. Cad Saude Publica 2016; 32: e00133215, doi: 10.1590/0102-311X00133215.

8. Han Z, Mulla S, Beyene J, Liao G, McDonald SD. Maternal underweight and the risk of preterm birth and low birth weight: a systematic review and meta-analyses. Int $J$ Epidemiol 2010; 40: 65-101, doi: 10.1093/ije/dyq195.

9. Yu Z, Han S, Zhu J, Sun X, Ji C, Guo X. Pre-pregnancy body mass index in relation to infant birth weight and offspring overweight/obesity: a systematic review and meta-analysis. PLoS One 2013; 8: e61627, doi: 10.1371/journal.pone. 0061627.

10. El Rafei R, Abbas HA, Charafeddine L, Nakad P, Al Bizri A, Hamod D, et al. Association of pre-pregnancy body mass index and gestational weight gain with preterm births and fetal size: an observational study from Lebanon. Paediatr Perinat Epidemiol 2016; 30: 38-45, doi: 10.1111/ppe. 12249.

11. Gaillard R, Durmuş B, Hofman A, MacKenbach JP, Steegers EAP, Jaddoe VWV. Risk factors and outcomes of maternal obesity and excessive weight gain during pregnancy. Obesity 2013; 21: 1046-1055, doi: 10.1002/oby.20088.

12. Deruelle P, Servan-Schreiber E, Riviere O, Garabedian C, Vendittelli F. Does a body mass index greater than $25 \mathrm{~kg} / \mathrm{m}^{2}$ increase maternal and neonatal morbidity? A French historical cohort study. J Gynecol Obstet Hum Reprod 2017; 46: 601-608, doi: 10.1016/j.jogoh.2017.06.007.

13. Subcomisión DOHaD - SAP "Origen de la Salud y Enfermedad en el Curso de la Vida" - Sociedad Argentina de Pediatria. Developmental Origins of Health and Disease Concept: The environment in the first 1000 days of life and its association with noncommunicable diseases [in Spanish]. Arch Argent Pediatr 2020; 118: S118-S129.

14. Monteiro CA, Conde WL, Popkin BM. The burden of disease from undernutrition and overnutrition in countries undergoing rapid nutrition transition: a view from Brazil. Am J Public Health 2004; 94: 433-434, doi: 10.2105/AJPH.94.3.433.

15. Instituto Brasileiro de Geografia e Estatística. Pesquisa nacional de saúde 2013: Ciclos de vida: Brasil e Grandes Regiões. Ministério da Saúde. 2015. https://biblioteca.ibge.gov. br/visualizacao/livros/liv94522. Accessed March 15, 2020.

16. Horta BL, Barros FC, Lima NP, Assunção MCF, Santos IS, Domingues MR, et al. Maternal anthropometry: Trends and inequalities in four population-based birth cohorts in Pelotas, Brazil, 1982-2015. Int J Epidemiol 2019; 48: i26-i36, doi: 10.1093/ije/dyy278.

17. da Silva AAM, Simões VMF, Barbieri MA, Cardoso VC, Alves CMC, Thomaz EBAF, et al. A protocol to identify nonclassical risk factors for preterm births: the Brazilian Ribeirão Preto and São Luís prenatal cohort (BRISA). Reprod Health 2014; 11: 79, doi: 10.1186/1742-4755-11-79.

18. World Health Organization. International statistical classification of diseases and related health problems, 10th revision. World Health Organization. 2016. https://www.who.int/classifi cations/icd/ICD10Volume2_en_2010. Accessed April 10, 2020.

19. World Health Organization. Physical status: the use and interpretation of anthropometry. Report of a WHO Expert Committee. World Health Organization Technical report series. 1995. https://apps.who.int/iris/handle/10665/37003. Accessed June 25, 2020.

20. Textor J, Hardt J, Knuppel S. DAGitty: a graphical tool for analyzing causal diagrams. Epidemiology 2011; 22: 745, doi: 10.1097/EDE.0b013e318225c2be.

21. Block G, Gillespie C, Rosenbaum EH, Jenson C. A rapid food screener to assess fat and fruit and vegetable intake. Am J Prev Med 2000; 18: 284-288, doi: 10.1016/S07493797(00)00119-7.

22. Craig $C L$, Marshall $A L$, Sjöström $M$, Bauman $A E$, Booth $M L$, Ainsworth $\mathrm{BE}$, et al. International physical activity questionnaire: 12-Country reliability and validity. Med Sci Sports Exerc 2003; 35: 1381-1395, doi: 10.1249/01.MSS.000007 8924.61453.FB

23. Rasmussen KM, Yaktine AL. Weight gain during pregnancy: Reexamining the guidelines. Washington: National Academies Press; 2009, doi: 10.17226/12584.

24. Popkin BM, Adair LS, Ng SW. Global nutrition transition and the pandemic of obesity in developing countries. Nutr Rev 2012; 70: 3-21, doi: 10.1111/j.1753-4887.2011.00456.x.

25. NCD Risk Factor Collaboration (NCD-Risk). Worldwide trends in body-mass index, underweight, overweight, and obesity from 1975 to 2016: a pooled analysis of 2416 population-based measurement studies in 128.9 million children, adolescents, and adults. Lancet 2017; 390: 26272642, doi: 10.1016/S0140-6736(17)32129-3.

26. Correia LL, da Silveira DMI, e Silva AC, Campos JS, Machado MMT, Rocha HAL, et al. Prevalência e determinantes de obesidade e sobrepeso em mulheres em idade reprodutiva residentes na região semiárida do Brasil [in Portuguese]. Cienc Saude Colet 2011; 16: 133-145, doi: 10.1590/S1413-81232011000100017.

27. Ferreira RAB, Benicio MHD. Obesidade em mulheres brasileiras: associação com paridade e nível socioeconômico [in Portuguese]. Rev Panam Salud Publical 2015; 37: 337-342. 
28. Lima RJCP, Batista RFL, Ribeiro MRC, Ribeiro CCC, Simões VMF, Neto PML, et al. Prepregnancy body mass index, gestational weight gain, and birth weight in the BRISA cohort. Rev Saude Publica 2018; 52: 46, doi: 10.11606/ S1518-8787.2018052000125.

29. Carnero AM, Mejía CR, García PJ. Rate of gestational weight gain, pre-pregnancy body mass index and preterm birth subtypes: a retrospective cohort study from Peru. BJOG 2012; 119: 924-935, doi: 10.1111/j.1471-0528.2012. 03345.x.

30. Soltani H, Lipoeto NI, Fair FJ, Kilner K, Yusrawati Y. Prepregnancy body mass index and gestational weight gain and their effects on pregnancy and birth outcomes: a cohort study in West Sumatra, Indonesia. BMC Womens Health 2017; 17: 102, doi: 10.1186/s12905-017-0455-2.

31. Starling AP, Brinton JT, Glueck DH, Shapiro AL, Harrod CS, Lynch AM, et al. Associations of maternal BMI and gestational weight gain with neonatal adiposity in the Healthy Start study. Am J Clin Nutr 2015; 101: 302-309, doi: 10.3945/ajcn.114.094946.

32. Bhattacharya S, Campbell DM, Liston WA, Bhattacharya S. Effect of Body Mass Index on pregnancy outcomes in nulliparous women delivering singleton babies. BMC Public Health 2007; 7: 168, doi: 10.1186/1471-2458-7-168.

33. Xu H, Arkema EV, Cnattingius S, Stephansson O, Johansson K. Gestational weight gain and delivery outcomes: a population-based cohort study. Paediatr Perinat Epidemiol 2020 (in press), doi: 10.1111/ppe.12709.

34. Liu L, Hong Z, Zhang L. Associations of prepregnancy body mass index and gestational weight gain with pregnancy outcomes in nulliparous women delivering single live babies. Sci Rep 2015; 5: 12863, doi: 10.1038/srep12863.

35. Fouelifack FY, Fouedjio JH, Fouogue JT, Sando Z, Fouelifa LD, Mbu RE. Associations of body mass index and gestational weight gain with term pregnancy outcomes in urban Cameroon: a retrospective cohort study in a tertiary hospital. BMC Res Notes 2015; 8: 806, doi: 10.1186/ s13104-015-1765-9.

36. da Silva AAM, Batista RFL, Simões VMF, Thomaz EBAF, Ribeiro CCC, Lamy Filho $F$, et al. Changes in perinatal health in two birth cohorts (1997/1998 and 2010) in São Luís, Maranhão State, Brazil. Cad Saude Publica 2015; 31: 1437-1450, doi: 10.1590/0102-311X00100314.

37. Silveira MF, Victora CG, Horta BL, da Silva BGC, Matijasevich A, Barros FC. Low birthweight and preterm birth: Trends and inequalities in four population-based birth cohorts in Pelotas, Brazil, 1982-2015. Int J Epidemiol 2019; 48: i46-i53, doi: 10.1093/ije/dyy106.

38. Lamy Filho F, Assunção AN, da Silva AAM, Lamy ZC, Barbieri MA, Bettiol $\mathrm{H}$. Social inequality and perinatal health: Comparison of three Brazilian cohorts. Braz J Med Biol Res 2007; 40: 1177-1186, doi: 10.1590/S0100-879X20060050 00154.

39. Hutcheon JA, Bodnar LM. Good practices for observational studies of maternal weight and weight gain in pregnancy. Paediatr Perinat Epidemiol 2018; 32: 152-160, doi: 10.1111/ ppe.12439.

40. Headen I, Cohen AK, Mujahid M, Abrams B. The accuracy of self-reported pregnancy-related weight: a systematic review. Obes Rev 2017; 18: 350-369, doi: 10.1111/obr.12486. 